\title{
Isolation and characterization of
} microsatellite loci in Sisyrinchium (Iridaceae) and cross amplification in other genera

\author{
R.B. Miz ${ }^{1}$, L.O. Tacuatiá1, F.W. Cidade 2 , A.P. de Souza ${ }^{2,3}$, F. Bered ${ }^{1}$, \\ L. Eggers ${ }^{4}$ and T.T. de Souza-Chies ${ }^{1,4}$ \\ ${ }^{1}$ Programa de Pós-Graduação em Genética e Biologia Molecular, \\ Instituto de Biociências, Universidade Federal do Rio Grande do Sul, \\ Porto Alegre, RS, Brasil \\ ${ }^{2}$ Centro de Biologia Molecular e Engenharia Genética, \\ Universidade Estadual de Campinas, Campinas, SP, Brasil \\ ${ }^{3}$ Departamento de Biologia Vegetal, Instituto de Biologia, \\ Universidade Estadual de Campinas, Campinas, SP, Brasil \\ ${ }^{4}$ Departamento de Botânica, Instituto de Biociências, \\ Universidade Federal do Rio Grande do Sul, Porto Alegre, RS, Brasil \\ Corresponding author: T.T. de Souza-Chies \\ E-mail: tatiana.chies@ufrgs.br
}

Genet. Mol. Res. 15 (3): gmr. 15038474

Received January 20, 2016

Accepted June 23, 2016

Published September 16, 2016

DOI http://dx.doi.org/10.4238/gmr.15038474

Copyright (C) 2016 The Authors. This is an open-access article distributed under the terms of the Creative Commons Attribution ShareAlike (CC BY-SA) 4.0 License.

\begin{abstract}
Recent phylogenetic studies on Sisyrinchium strongly suggest that species classified in section Hydastylus and section Viperella belong to a single group of plants in recent adaptive radiation (Clade IV). These species neither present clear morphological differentiation among them nor show clear identification using DNA barcode markers. Thus, the main goal of this study was to develop a set of polymorphic microsatellite markers compatible for representative
\end{abstract}


species of both sections to ensure variability that could be revealed by SSR markers. Therefore, microsatellite primers were isolated and characterized for Sisyrinchium palmifolium and S. marchioides. In addition, transferability of the developed primers was tested in Iridoideae, primarily in closely related species of Sisyrinchium. Sixteen microsatellite loci were developed from enriched genomic libraries, of which ten were polymorphic. $G_{\mathrm{ST}}$ values indicated higher differentiation among subpopulations of S. palmifolium than those from S. marchioides. Major transferability was obtained using primers isolated from $S$. marchioides. All primers exhibited higher rates of cross-amplification for species belonging to Clade IV of Sisyrinchium, as well as to the genera Calydorea and Herbertia. These developed microsatellite markers can be used as an efficient tool for characterization of genetic variability in species belonging to Iridoideae, as well as for studies on population dynamics, genetic structure, and mating system in other Sisyrinchium species.

Key words: Sisyrinchium palmifolium; Sisyrinchium marchioides; Genetic diversity; Iridaceae; Microsatellite 